\title{
CIBERSOCIEDAD, NET ART, CIBERFEMINISMO Y CIBERCULTURA: EL CUERPO EN INTERNET
}

\author{
Almudena García Manso \\ Universidad Alfonso X el Sabio (UAX), España.
}

\section{Resumen:}

La expresión artística en el ciberespacio da a conocer una nueva imagen del cuerpo, icono por ende del arte a lo largo de la historia de la humanidad, dicho icono ve cómo su dimensión se modifica merced el uso de las Tecnologías de la Información y las Comunicaciones. Las posibilidades que estas tecnologías proporcionan han posibilitado un cuerpo obra de arte en el ciberespacio, merced a las performances propias del Net Art. El cuerpo y la obra de arte en esta dimensión virtual adquiere una dimensión de deslocalización que antes no poseían.

Así como el Net Art ciberfeminista permite una visión de la identidad de género virtual que viene dado por la performatividad de la representación corporal de los sujetos mediante el Net art.

Palabras clave: Internet - Net.art - Cibercultura - Cuerpo - ComunicaciónCibersociedad - Ciberfeminismo

\section{INTRODUCCIÓN: ARTE Y CUERPO}

El desarrollo y proliferación de las nuevas Tecnologías de la Información y las Comunicaciones nos conducen a la idea de una sociedad donde el ser humano es enteramente dependiente de las tecnologías telemáticas y de la información. Dependencia que no es más que un síntoma del desarrollo propio de la Sociedad de la Información (Joyanes, 1997). Desarrollo y dependencia que denotan la inclusión del individuo social en el ciberespacio y una situación de no retorno a épocas sociales pre internet. Esta situación da lugar a la existencia del espacio social en Internet -la cibersociedad -

La cibersoceidad posee una serie de características que hacen que la expresión comunicativa e informativa, incluyendo la expresión artística, subjetiva e identitaria de los sujetos tenga unas dimensiones que se escapan a las de la realidad social, física y tangible. Por un lado debemos resaltar la glocalidad de la información, interacción y comunicación en la cibersociedad, deslocalizar y relocalizar, internacionalizar y "regionalizar" la comunicación e internación, todo ello a la vez es una de las características que hacen de Internet uno de los medios más potentes e insuperables. Esta capacidad hace más atractiva la Red como medio de expresión y reivindicación social, artística y política de manera glocal, amplificada y dispuesta a todos los niveles, el internacional y el regional-local. La comunicación y la información en Internet se haya deslocalizada, únicamente localizada técnicamente los nodos si pueden ser localizados mediante la ubicación del servidor- pero no podemos localizarlos a vista de Interface Gráfico de Usuario, es decir a modo usuario no sabemos si la información a la que estamos accediendo es de nuestro contexto socio-cultural o procede de una cultura y un contexto diferente.

La atemporalidad del contenido comunicativo, informativo e interactivo también es

Recibido: 01/03/1999---Aceptado: 16/04/1999---Publicado: 12/11/1999 
otra de las características que hacen de la cibersociedad un espacio social altamente atractivo para la expresión social, política y artística. La capacidad que las herramientas de comunicación social de Internet permiten que la comunicacióninteracción y la información se transmita en tiempo interactivo real -como es el caso de los CHAT o la mensajería instantánea- o fuera del tiempo interactivo real como es el caso de los correos electrónicos y las páginas web, además existe la capacidad de estar dentro y fuera de ese tiempo interactivo real, el ejemplo de ello lo encontramos con los foros de comunicación, en estos espacios comunicativos sociales un usuario puede acceder a la información interactiva a posteriori de que ésta se dé o en el mismo instante, independientemente de la ubicación geográfica y la franja horaria en la que esté su interlocutor.

La a geografía es otro de las características que nos permite ver a Internet y por extensión a su escenario social la cibersociedad a modo de espacio ideal para la transgresión comunicativa e informativa que supone ser el Net.art de carácter ciberfeminista.

Como últimas características señalar la del anonimato comunicativo o "mascarada virtual" (Turkle, 1997) la cual hace mención a la identidad que uno crea en Internet, identidad que es modelada lejos de la identidad física y real, pero que sí posee una relación en cuanto a lo que puede esconder del auténtico deseo sobre la subjetividad e identidad de uno mismo.

Similar a las mascaradas isabelinas de la Ópera que permitían ocultar el auténtico rostro de la persona y ser por unos instantes uno mismo o quien quieras ser, la "mascarada virtual" permite esconder tras ceros y unos la verdad o mentira de una persona. Convertir su identidad en un ciborg -hibridar los deseos reales con la verdad tecnológica-.

La capacidad multimedia e hipermedia en la transmisión de los datos es una de las características que hacen de Internet un espacio social atractivo y factible de ser escenario de de-codificaciones de realidades. Permitir el uso de datos audio, texto, imagen, video en un único medio da pie a la apertura de oportunidades de recodificación, de-codificación y codificación de datos. La mediación tecnológica y la modificación de la misma y en múltiples formatos permite esa alteración de lo que significa, del significado y del significante del hecho representado. Una alteración libre que está vedada a aquellos/as que conocen las tecnologías. Algo que queda latente en las acciones ciberfeministas y Net.artísticas de las VNS Matrix (VNS Matrix, 1993) y en demás ciberfeministas que comenzaron a utilizar Intenet y la cibersociedad como medio de transgresión artística en busca de una reivindicación feminista (Stone, 1991).

El tránsito de un arte dislocado espacialmente a un arte dislocado de forma temporal radicó en el paso del arte abstracto y el cubismo al Net Art, este último no es otra cosa que la representación de las acciones virtualizadas o simuladas mientras estas suceden o sucedieron, pero no nos referimos a una virtualización similar a la que sucede con la representación fotográfica o cinematográfica, las cuales muestran un acto o acción/hecho que primero se realiza y posteriormente se contempla y expone, el Net Art no es un arte que se produce en tiempo diferido, sino que no tiene tiempo real de producción, no concibe el concepto de reproducción temporal, por que o bien puede ser reproducido posteriormente a la acción, en tiempo interactivo real sin que 
el usuario sepa la situación temporal de la representación (Dery, 1998). En el arte en general en las sociedades anteriores a las TICs la velocidad era relativa, todo arte ha tenido un tiempo interno relativo, muy típico en la danza y en la música pero que también acontecía en la pintura, la traslación del arte a la sociedad Internet hace que esta velocidad se convierta en absoluta, lo cual rompe con la barrera del tiempo. La virtualidad viene a convertirse en la velocidad electromagnética que conduce al límite de la aceleración, una barrera infranqueable que se cristaliza en la posible o dudosa transmisión en directo de los hechos o actos artísticos de la performance o representación en general. El tiempo global de la intercomunicación que se efectúa de manera instantánea y que demuestra cómo una de las barreras del arte en general, y en particular la concepción del arte no virtualizado, es el tiempo y la representacióndel mismo.

La materia, el cuerpo, lo físico, tangible, orgánico y material son los materiales de inscripción y representación del cuerpo, un emplazamiento y fijación material, puramente localizable en el espacio y en el tiempo, este arte no era algo que se separaba de la localización de la obra que representaba, así como no se separaban del cuerpo del ser humano, un cuerpo marcado, tatuado así como el cuerpo representado en cualquier obra de arte.

En todas las expresiones artísticas se encuentra la localización fija, sólo con el transcurso del tiempo se ha iniciado la deslocalización, con los primeros cuadros que se liberaron de la cueva o de la piel, convirtiéndose en objetos desplazables y nómadas. Deslocalización relativa, que ni tan siquiera perdía el lugar, siendo únicamente una posibilidad de movimiento. Las pinturas, esculturas y edificios arquitectónicos se hayan inscritos en el material que los cristaliza y compone, puede deslocalizarse el sentido de la obra, pero no la obra de arte en sí. Deslocalización ante la que se encuentra el arte actual, es una deslocalización en su más amplio sentido, absoluta, sin lugar, el arte no está en ningún sitio, no existe más que como emisión y recepción de una señal, en el feedback que denota el arte en la Red, el arte de la realidad virtual es un arte de la retroalimentación.

Esta deslocalización no es más que la antesala del arte actual, del Net.art o demás movimientos artísticos sustentados en la Red, que inicia desde su inicial inscripción en un lugar, a través de museos, galerías o colecciones itinerantes, más tarde a través de reproducciones fotográficas y del CD-rom, soportas que aún siguen siendo materiales, localizables y limitados en el tiempo. El arte en la Red, con sus técnicas interactivas alcanza un nivel de intercambio instantáneo entre el actor y el espectador, denotando la deslocalización final.

La moderna descomposición en el arte, como lo es el puntillismo, el cubismo, la abstracción o el divisionismo, manifiesta otro tipo de deslocalización que se manifiesta en el arte en la Red, en esta deslocalización los signos no existen como figuras propiamente dichas, son figuras rotas, un proceso de descomposición que culmina en la imagen fractal y en el gráfico del ordenador, procediéndose a un paso de la descomposición moderna a lo fractal, la imagen digital que deja paso a la absoluta virtualización, la emisión y recepción de imágenes que son completamente instrumentales.

Para comprender lo que conlleva la deslocalización, tomemos el cuerpo como elemento de expresión artística y como este, a través de su iniciación en el mundo 
del arte en la Red, se ha deslocalizado igualmente, tomando una dimensión anteriormente no dada, la dimensión de trascender lo local y lo espacial, así como romper con su inmutablidad como expresión artística. La importancia del cuerpo en el arte de internet o Net.art deriva del valor político del cuerpo en la historia, en las sociedades, el cuerpo no es una mera carcasa de carne que alberga un alma y que hace del sujeto un ser a los ojos de un dios. El cuerpo es uno de los ejes centrales del dominio, del poder, la política y la ideología. La anatomopolítica y la biopolítica (Foucault, 1994) dan muestras de cómo el cuerpo es sometido a unas tecnologías de poder que hacen que el sujeto esté sujetado a unas ideologías e intereses que harán que el sujeto actúe conforme a esos intereses mediante el sometimiento de su corporalidad y la importancia que éste tiene para el dominio del poder.

Así como el cuerpo siempre ha sido objeto del arte, pues el arte está íntimamente ligado con la sociedad que representa, con sus intereses y con sus ideales. La modificación por los tatuajes, su encarnación en los cuadros, esculturas, textos y obras arquitectónicas, han permitido que este forme parte de todos los movimientos artísticos acontecidos a lo largo de la historia de la humanidad, y como tal no va a dejar de serlo en la era de la Información y las Comunicaciones.

La diferencia del cuerpo representado en los demás movimientos artísticos y el cuerpo representado en el arte Red, viene dada por las características propias del medio en el cual se expresa y reproduce, el ciberespacio y su carácter interactivo, procediendo de nuevo a la deslocalización completa y total del objeto artístico, de su significado y de los elementos que participan de la toda obra de arte: espectador, artista, material, significado y la misma obra de arte. Una deslocalización y dislocación donde no hay lugares específicos, simplemente la emisión y recepción de sensaciones que van más allá del objeto singular.

Un cuerpo que no solo se haya ante su propia deslocalización, derrumbando las barreras del espacio, el tiempo y lo material, sino que es deconstruible, representable, modificable, tomando dimensiones varias que afectan a la configuración de nuevas subjetividades e identidades, un cuerpo que se nutre de la acción interactiva.

La conexión actual del cuerpo, el arte y la tecnología ampara la idea del reemplazo del cuerpo por la máquina, del cuerpo orgánico por el cuerpo virtual como estética artística y crítica social.

\section{CIBERCULTURA Y CUERPO.}

La cibercultura y el net art aborda el tema del cuerpo, en su mayoría, desde una perspectiva imaginaria del mismo, su proyección, su traslación a través del ciberespacio, más allá de las limitaciones espaciales a las que el ser humano está acostumbrado, a pesar de lo cual se erige otro cuerpo cuya resonancia cultural no es muy explícita pero se va demarcando como lo culturalmente nuevo, un cuerpo narcisizado, elevado a categoría de culto, de arte, de extinción de diferencias, capaz de romper con las leyes de la física y ser moldeado, descubierto como un icono de referencia para la subjetividad del individuo, de estrategia de acción social, un cuerpo nuevo que hace referente a una nueva cultura: la cibercultura.

El cuerpo de la comunicación mediada a través de la Red, es un cuerpo 
interconectado, una vivencia actual, influida por los nuevos contextos socioculturales de influencia tecnológica y virtual. Una de las definiciones que se puede establecer del concepto de hipocuerpo es aquella que lo considera como una vivencia dramática frente a la toma de conciencia de tener un cuerpo único, limitado y no múltiples, una carencia del mismo, mostrándose como la contra cara, el aspecto negativo de la des corporeización de las redes. La licuación del cuerpo que posteriormente genera la vivencia del hipocuerpo.

El tema del cuerpo en la Red se aborda tomando en cuenta la dimensión de traslación, posibilitada por las tecnologías de la comunicación y la información. El flujo de información y los intercambios textuales a través de las redes telemáticas han dado pie a múltiples trabajos en donde el cuerpo se cuestiona en su aspecto tangible, las posibilidades de control y manejo de la identidad, las presentaciones 0 representaciones de cuerpos- imagen-dato susceptibles de modificación, las relaciones y lazos sociales generados en los entornos interactivos de comunicación, la posibilidad de realizar activismo y reivindicación social, el hecho de tomar el cuerpo como icono artístico, icono pornográfico y sexual, proporciona nuevas concepciones posibles en torno al cuerpo, generadas e incentivadas merced a la Red y su naturaleza, consistentemente virtual, comunicativa y de trasmisión o flujo de información.

El contexto ciberespacial se muestra como un entorno donde es posible ladear al cuerpo real, material, permitiendo una relación con los otros, cuerpos como él pero de formato bite, sin que importen las distancias y limitaciones físicas existentes (Rheingold, 1993), afirmando el inminente anonimato que infiere la interacción social en la Red, una marca de la dimensión imaginaria en donde el cuerpo, sus marcas, sus posibles estigmas, dejan de contar en el encuentro, a diferencia de las interacciones cara a cara (Goffman, 1959).

En este tipo de imaginario de traslación del cuerpo en el ciberespacio, el cambio de los rasgos corporales y la identidad social individual puede anularse, camuflarse e incluso cambiarse, un juego que es acopiado por el Net.art y diversas expresiones artísticas, que gracias al cual se permite no sólo expresar las capacidades artísticas sino también ejercer la acción y reivindicación social. Las diferencias genéricas, de edad, de raza, estéticas o morfológicas trascienden, al igual que la totalidad del cuerpo, la frontera, dispersándose en el espacio virtual imaginado, donde cabe la posibilidad de pasar de una máquina a otra, de un lugar geográfico a otro, de un individuo a otro, rompiendo las barreras de lo real, del espacio y del tiempo. Un mundo silencioso, tal y como lo definió Barlow (Jones,1997) donde la única capacidad de comunicación es la escrita o la icónica, un espacio que para entrar el individuo se ve en la obligación de abandonar cuerpo y lugar teniendo que adecuarse a comunicarse vía texto, imagen y sonido. Un espacio donde se da lugar el "metahombre" (Piscitelli, 1995), un individuo que puede trascender el tiempo y el espacio y que junto con las posibilidades inferidas por las tecnologías de la nanotecnología y la colación proponen una eficaz salida contra el paso del tiempo, un envejecimiento postergado que se encamina hacia la juventud perpetua, desafiando las limitaciones del cuerpo único.

La virtualización del cuerpo y las dinámicas de interioridad y exterioridad que las nuevas tecnologías en el campo de la medicina han hecho posibles, tomando como 
modelo la cinta de Moebius. El cuerpo se ha exteriorizado, se ha hecho público lo interno y lo público se ha vuelto privado, al igual que ha procedido en los bancos de órganos, semen o sangre. Los límites entre lo externo y lo interno se vuelven cada vez más difusas en un continuo, lo que ha llevado a Pierre Levy (1995) a plantear la noción de "hipocuerpo".

Todos los componentes del cuerpo en el preciso instante de exponerse de forma común, abandona la intimidad subjetiva y pasan al exterior, un cuerpo público que se trasplanta en el individuo, hecho que hace constancia en el preciso momento en el que los seres sociales se asocian virtualmente, a un cuerpo articulado con los demás participes de las redes, configurándose a modo de cuerpos externos, maleables y susceptibles de lo público. Cada cuerpo individual se convierte en parte receptora de un inmenso hipercuerpo híbrido y mundializado, que se cristaliza en la inmensidad de Internet.

Este paradigma viene a indicar el final de la humanidad biológica como vanguardia de la evolución, una próxima etapa evolutiva en la sociedad que se visualiza como una hibridación entre lo humano y lo tecnológico, sólo tangible a través de las expresiones artísticas vía Red.

\section{CONCLUSIONES: CIBERFEMINISMO, NET.ART E IDENTIDAD DE GÉNERO/CUERPO}

El ciberfeminismo, retoma las palabras de Kurzweil (1999) y las de Haraway (1995), pensando en un esquema de sociedad genérica sin géneros, donde la naturaleza sea reinventada, un cuerpo cyborg, que hace constancia en el movimiento artístico ciberfeminista y en sus net.artistas, que unidas a la idea de cuerpo obsoleto propio del movimiento ciberpunk, hacen referencia de cómo los individuos deben mencionar al cuerpo y no a su cuerpo, mostrándolo en diferentes situaciones que intentan dar cuenta de dicha obsolescencia, borrando los resquicios y restos modernistas (Kember, 1998).

Las posibilidades que se han abierto a través de la comunicación mediada por ordenador (CMC) relacionadas al cuerpo, y las posibilidades de escapar a las limitaciones del espacio real de las categorías de cuerpo y espacio, tal y como se conocen hoy en día, han posibilitado la traspolación de nuestros sentidos hacia un espacio infinito (Kerckhove, 1995), es la virtualización la que ha permitido ir más allá de la piel, más allá de ese límite, para desplegarse en una piel colectiva, una piel que traspasa todas las fronteras físicas, subjetivas, espaciales, temporales e incluso individuales, reconstruyendo un cuerpo humano y tecnológico, que es capaz de trascender a lo largo y ancho del ciberespacio.

Las posibilidades que abre la comunicación mediada por computador al cuerpo, sus posibilidades de escapar a las limitaciones del espacio real de las categorías tradicionales de espacio y tiempo, se perciben en toda la evolución y desarrollo de los movimientos artísticos en la Red, el net art y especialmente la acción de I@s artist@s ciberfeministas, que con sus obras de arte de trasfondo social han permitido un escape del cuerpo en doble sentido, por un lado afirmar los presupuestos de Levy y Kerckhove el inicio a una traspolación de los sentidos hacia un espacio infinito y la 
posible ruptura del binarismo tradicional del género, que conduce hacia una reinvención de la naturaleza inscrita en el cuerpo. Esta virtualización permite trascender el cuerpo construido culturalmente y trascender el cuerpo natural biológico, hacia una reconstrucción del mismo, que desdeña la aptitud cartesiana que recalca al cuerpo como la parte del ser humano inmutable e inmodificable.

Una virtualización que alumbra una posibilidad de ir más allá de la piel, de lo orgánico, natural y biológico, superando el límite de lo corpóreo y lo limitado, con el fin de desplegarse en una piel colectiva, un organismo plural e ilimitado por la naturaleza y sus leyes espacio temporales.

Esa piel colectiva, se percibe en el net art como la opción de acceso a la obra de arte plural, una expresión artística, que al igual que la comunicación e interacción procedida en la Red, es ilimitada en cuanto a participantes, infinita como el hipertexto en el que se sustenta, moldeable por la piel colectiva que compone el cuerpo humano en la Red. En este contexto artístico la confluencia se da en la hibridación por la que se compone y traduce la obra de arte, una hibridación donde se confunde el artista, el espectador, la obra de arte y la interpretación de la misma, lo cual refuerza aún más si cabe la idea de piel colectiva, hibridación que caracteriza el cuerpo en la Red, un cuerpo artístico, donde se entrelaza la fantasía, la vivencia de un cuerpo, la posibilidad de trascender los límites corporales, que visualiza dicho contexto descorporeizando y multicorporeizando virtualmente, en representaciones gráficas, proyecciones corporales, avatares que no tienen justificación en el cuerpo físico. El arte del cuerpo, el arte Red que modifica el cuerpo y le concede una nueva posición sustancial es un arte donde confluye la fantasía y la realidad (Elliot, 1996).

En Internet el mundo existe únicamente en las representaciones de los individuos, representantes temporales, que se trasladan en la información, los datos y las imágenes vía mail, chat, en la www, en la interacción no concluida. El mundo en Internet es una estela que se autodestruye en el preciso instante en el que finaliza la comunicación. En Internet la percepción de las texturas conforma las múltiples posibles formas de ser y hacer en la Red, son las que liberan el inconsciente, texturas que se convierten en autónomos que desbordan el cuerpo, bien sea para destruirlo, reestablecerlo o elevarlo tal y como sucede con el arte en la Red.

En el ciberespacio los individuos son cuerpos realizados a través de la máquina, con palabras e imágenes, con fusiones y códigos que los inscriben social y culturalmente a través de la tecno anatomía que ejecuta el net art, las herramientas comunicativas y de diseño gráfico es a la expresión artística y a la vida digital un efectivo bisturí qué mediante el código y palabras, modela sujetos online con fines artísticos y reivindicativos.

La visión de un cuerpo que no posee una identidad corporal fija da pie a la conformación de sujetos libres de identidad genérica, los Cyborgs que no se inscriben en la corporalidad y cardinalidad, al tratarse de sujetos híbridos su identidad será conformada por la hibridación que los conforma (Colaizzi, 1995).

Una identificación territorial que traspasa las fronteras del ciberespacio para pasar a la acción feminista, a la vida tangible, utilizando como medio trasmisor las redes de comunicación telemáticas, haciéndolas suyas, identificándolas como un elemento de poder femenino y feminista, de ahí las numerosas manifestaciones de reivindicación feminista mediadas por Internet, que conforman desde grupos o asociaciones, 
páginas web de información y representación, comunidades virtuales hasta el arte en la Red o Net Art, ejercicio artístico que se identifica de forma muy clara con el ciberfeminismo y la posibilidad de acción social, expresión artística que rompe con todo lo establecido en el arte tradicional, y que merced a sus características específicas, principalmente la a geografía de la obra de arte, la inexistente identidad de autor, o mejor dicho la posibilidad de la multiplicidad de autoría, la desmaterialización de la obra de arte y la inexistencia de un soporte físico como tal, proporcionan una nueva dimensión que ha sido utilizada por el ciberfeminismo en sus representaciones artísticas de demanda y protesta social, la tras localización y la libertad que se trasfirió en los orígenes del Net Art ciberfeminista abrió las puertas a una novedosa visión del género, únicamente simbólico y representativo. El universo femenino de la máquina y la tecnología abierto por Sadie Plant muestra un fuerte paso del feminismo tecnófobo al ciberfeminismo como una puerta abierta a futuras tendencias y modos de acción y expresión feministas. La mezcla que efectúa Plant entre la historia de la tecnología femenina y lo que esto supuso en la gestación de las nuevas tecnologías, así como la ruptura con el pensamiento lineal en post de una estructura hipertextual, que influye en la forma en la que son vistos los dualismos genéricos, tachados de antagónicos y que tras las dilucidaciones de Plant referentes a las dimensiones que adquiere el cero femenino frente al uno masculino.

El nexo de unión entre las mujeres y los ordenadores es situado, no de forma única en la ruptura con el binarismo tradicional de lo único frente a lo otro, sino que Plant sitúa ese nexo en la Matriz, la Red que se instituye como el compendio de la nueva distribución no lineal del mundo, el hipertexto y sus rasgos hacen que Internet se torne en un caldo de cultivo hábil para la formación de otras identidades de género, de otros géneros y de una extinción de los binarismos en post de lo que podría abarcar la imagen Cyborg: la mutabilidad, la maleabilidad, fluidez, conexión entre hombre y máquina, enmarañamiento de los límites que separan lo natural y lo virtual o tecnológico, la traslación que permite una excesiva libertad de movimiento y desplazamiento, "un individuo puede convertirse en una explosión demográfica en la Red: muchos sexos, muchas especies. Sobre el papel no existen límites a los juegos que se pueden jugar en el ciberespacio" (Plant, 1997: 65).

Un lugar "que se define como urdimbre infinita de relaciones en ausencia de jerarquías, un lugar cuya estructura excusa, en principio, la presencia de cualquier determinación falocéntrica" (Plant, 1997: 76) Sadie Plant desde estos supuestos abrió la polémica de vital importancia en el desarrollo de las estrategias de las mujeres y el feminismo en comunión con las Nuevas Tecnologías de la Información y las Comunicaciones, cuestionando la tecnofobia inherente a grupos feministas participes de una ultra valoración de lo natural, una tendencia a apreciar y a volver a lo extremadamente natural causada por la desconfianza hacia las máquinas junto a la consideración de los problemas reales que efectivamente el uso perverso de las mismas máquinas puede plantear, acrecentando el peligro de que se procediese a una brecha insondable entre el feminismo tecnófobo y el ciberfeminismo.

Además de las capacidades del medio, las posibilidades del nuevo espacio se consideraban dependientes de su uso, manejo y utilización "la incorporación del cuerpo en el espacio virtual genera significados imprevistos a través de la articulación de diferencias entre cuerpos y no cuerpos, espacio y no espacios"(Stone, 1992), una visión esta de las tecnologías como agentes no trasparentes, es decir no pueden 
eliminar el problema de la diferencia sexual, más bien son medios que promueves la producción de cuerpos sexuados en el ciberespacio, aumentando si cabe más la proliferación de imágenes degradantes de la mujer, cosificando, convirtiendo las imágenes de los cuerpos digitalizados en mercancías hábiles para la comercialización sexual y pornógrafa.

El impacto real de esta situación de tecnologización y conexión del mundo de las mujeres se intenta reflejar no sólo la vida cotidiana y laboral de las mujeres y las tecnologías, sino una forma más de activismo "El ciberfeminismo está clarificado en qué consisten las relaciones corrientes de las mujeres con la tecnología al igual que critica las estructuras de género en la cultura electrónica. Las mujeres desde su incorporación al trabajo están acostumbradas al empleo de tecnologías electrónicas, dad la distribución de puestos de trabajo atendiendo al género las mujeres han desempeñado la mayoría del trabajo de oficina utilizando máquinas de escribir, faxes, ordenadores, y teléfonos.

Pero de nuevo trabajos de segunda categoría. Como si fuera un círculo vicioso del cual resulta imposible salir, la relación de la mujer con la tecnología se complica, además, porque al producirse una mayor tecnologización de las empresas se produce inevitablemente una pérdida de empleo femenino. $Y$ esto contribuye en buena medida a la desaparición, una vez más, de las mujeres de la vida pública. Hoy en día, muchas mujeres buscan trabajo remunerado para realizar en la esfera privada del teletrabajo" (Martínez Collado, 1997) la complicación y sutileza que ha ido adquiriendo la Red tienden más a dificultar que a ayudar, manteniendo oculto el desarrollo de la mujer en la vida pública.

\section{BIBLIOGRAFÍA.}

Colaizzi, G. (1995). The cyborguesque. Valencia: Episteme.

Dery, M. (1998). Velocidad de Escape: la cibercultura en el final de siglo. Barcelona: Siruela.

Elliot, A. (1996) Sujetos a nuestro propio y múltiple ser. Buenos Aires: Amorrortu Editores

Foucault, M. (1994). La Historia de la Sexualidad: La voluntad del Saber. Vol I. Madrid: Siglo XXI.

Goffman, E. (1959) Presentation of Self in Everyday Life. New York: Anchor Books

Haraway, D. (1995). Ciencia, Cyborg y Mujeres: La Reinvención de la Naturaleza, Madrid: Ediciones Cátedra

Jones, S. (1997) Virtual Culture Identity and Communication in Cyberspace. London: Sage Pub

Joyanes, L. (1997). Cibersociedad los retos sociales del siglo XXI. Madrid: MacGraw Hill. 
Kember, S. (1998). "Feminismo, Tecnología y Representación". En: Curran, M \& Walkerdine, J (Comps.) Estudios Culturales y Comunicación. Barcelona: Paidós.

Kurzweil, R (1999). La era de las máquinas espirituales. Barcelona:

Planeta. Levy, P. (1995). ¿Qué es lo virtual?. Barcelona: Paidós

Martinez-Collado, A. 12/02/97: Perspectivas Feministas en el arte actual, http://www.estudiosonline.net/texts/perspectivas.html.

Pedraza, P. (1998). Máquinas de amar. Secretos del cuerpo artificial. Madrid:

Valdemar. Piscitelli, A. (1995). Ciberculturas En la era de las máquinas inteligentes.

Buenos Aires:

Paidós Contextos.

Plant, S. (1997). Ceros + Unos: Mujeres digitales + la nueva tecnocultura. Barcelona: Destino.

Rheingold, H. (1993) The Virtual Community. Homesteading on the Electronic Frontier.

New York: Harper Perennial

Stone, S. (1992). "Will the real Body Please Stand Up?". En Benedikt, M. Cyberespace, First Steps, Cambridge: MITT Press.

Turkle, S. (1997). La vida en la pantalla. Barcelona: Paidos.

VNS Matrix (1993). Brave new girls. Sidney: Experimental Art Foundation 